Review

\title{
Nanobody: The "Magic Bullet” for Molecular Imaging?
}

\author{
Rubel Chakravarty ${ }^{1,2,}$, Shreya Goel ${ }^{3}$, Weibo Cai $1,3,4,5, \llbracket$ \\ 1. Department of Radiology, University of Wisconsin - Madison, WI, USA \\ 2. Isotope Applications and Radiopharmaceuticals Division, Bhabha Atomic Research Centre, Mumbai, India \\ 3. Materials Science Program, University of Wisconsin-Madison, WI, USA \\ 4. Department of Medical Physics, University of Wisconsin - Madison, WI, USA \\ 5. University of Wisconsin Carbone Cancer Center, Madison, WI, USA
}

\begin{abstract}
$\square$ Corresponding author: Rubel Chakravarty, PhD, Isotope Applications and Radiopharmaceuticals Division, Bhabha Atomic Research Centre, Mumbai 400 085, India. Email: rubelc@barc.gov.in; Phone: +91-22-25590624. Or Weibo Cai, PhD, Departments of Radiology and Medical Physics, University of Wisconsin - Madison, Room 7137, 1111 Highland Avenue, Madison, WI 53705-2275, USA. Email: wcai@uwhealth.org; Phone: 608-262-1749; Fax: 608-265-0614
\end{abstract}

(C) Ivyspring International Publisher. This is an open-access article distributed under the terms of the Creative Commons License (http://creativecommons.org/ licenses/by-nc-nd/3.0/). Reproduction is permitted for personal, noncommercial use, provided that the article is in whole, unmodified, and properly cited.

Received: 2013.10.29; Accepted: 2014.01.07; Published: 2014.01.29

\begin{abstract}
Molecular imaging involves the non-invasive investigation of biological processes in vivo at the cellular and molecular level, which can play diverse roles in better understanding and treatment of various diseases. Recently, single domain antigen-binding fragments known as 'nanobodies' were bioengineered and tested for molecular imaging applications. Small molecular size $(\sim 15 \mathrm{kDa})$ and suitable configuration of the complementarity determining regions (CDRs) of nanobodies offer many desirable features suitable for imaging applications, such as rapid targeting and fast blood clearance, high solubility, high stability, easy cloning, modular nature, and the capability of binding to cavities and difficult-to-access antigens. Using nanobody-based probes, several imaging techniques such as radionuclide-based, optical and ultrasound have been employed for visualization of target expression in various disease models. This review summarizes the recent developments in the use of nanobody-based probes for molecular imaging applications. The preclinical data reported to date are quite promising, and it is expected that nanobody-based molecular imaging agents will play an important role in the diagnosis and management of various diseases.
\end{abstract}

Key words: Nanobody, molecular imaging, cancer, arthritis, atherosclerosis, positron emission tomography (PET)

\section{Introduction}

As one of the most exciting and rapidly growing areas of science, molecular imaging has become an indispensable tool in cancer research, clinical trials and medical practice [1-11]. During the last several decades, there has been remarkable progresses in the number of imaging technologies and their applications, with the objective of developing a new generation of platforms with greater accuracy and sensitivity for in vivo characterization and quantification of various biological processes [12]. Using an array of imaging techniques such as positron emission tomography (PET), single photon emission computed to- mography (SPECT), computed tomography (CT), magnetic resonance imaging (MRI), optical, ultrasound (US), photoacoustic imaging etc., researchers can now measure various dynamic biological processes in intact living subjects [1-3, 6-8, 12]. Molecular imaging provides the opportunity for understanding the underlying biology, early detection and characterization of various diseases, and evaluation of the therapeutic responses. However, no single imaging modality can provide information on all aspects of structure and function. Therefore, investigation of a subject using multiple imaging modalities is highly 
desirable and has gained increasing popularity [13-17].

Regardless of the modality used, molecular imaging generally requires accumulation of the signal delivered by a probe at the target site. The major challenge associated with non-invasive in vivo imaging is to achieve a high contrast signal over nearby healthy tissues, in addition to the issues related to biocompatibility, toxicity and probe stability. In order to achieve high target to non-target ratio, the imaging tags are generally coupled with various targeting molecules such as antibodies [18], peptides [19, 20], small molecule ligands [21], aptamers [22, 23], etc. Among these, monoclonal antibodies (mAbs) have long been considered as attractive candidates for both targeted therapy as well as diagnostics due to their exquisite specificity towards cognate antigens. However, the utility of mAbs for imaging is limited by their large size $(150 \mathrm{kDa})$, which leads to long circulation time in blood (e.g. a few days to weeks) and longer time to optimally accrete in the tumor tissue (typically several days). Advancement in antibody engineering has led to improvement in antibody pharmacokinetics without compromising its affinity and specificity [24, 25]. In this direction, numerous antibody fragments and variants such as $\mathrm{Fab}, \mathrm{F}\left(\mathrm{ab}^{\prime}\right)_{2}$, single chain $\mathrm{Fv}(\mathrm{scFv})$, diabodies and minibodies (molecular weight ranging from $25-100 \mathrm{kDa}$ ) were bioengineered [24-26]. In addition, the development of several non-traditional protein scaffolds such as domain antibodies, affibodies, nanobodies, and anticalins have been reported [24-26].

The methods of obtaining engineered antibodies and recombinant antibody fragments, as well as their use as probes or vectors for non-invasive imaging and therapeutic applications, have been extensively reviewed [24, 25, 27, 28]. Recently, there has been significant interest in the utilization of nanobodies (derived from heavy chain-only antibodies occurring naturally in Camelidae) for molecular imaging investigations, using modalities such as radionuclide-based, optical and ultrasound imaging [29-33]. In this review, we aim to provide a timely and comprehensive overview of the progress in the use of nanobodies in molecular imaging studies to date.

\section{Nanobodies}

Nanobodies are recombinant, single-domain, variable fragments of camelid heavy chain-only antibodies $(\sim 95 \mathrm{kDa})$, which are able to bind selectively to a specific antigen [34]. Typically, nanobodies are the variable domain alone of heavy chain antibodies (i.e. $\mathrm{V}_{\mathrm{H}} \mathrm{H}$ ) with approximate molecular weight of 12-15 $\mathrm{kDa}$ and are considered the smallest naturally derived antigen-binding fragment (Figure 1). The investiga- tion of the crystal structures of $\mathrm{V}_{\mathrm{H}} \mathrm{Hs}$ revealed a prolate (rugby ball) shape of approximately $2.5 \mathrm{~nm}$ in diameter and $4.2 \mathrm{~nm}$ in length $[35,36]$. Because of their size in the nm range, the term 'nanobody' was coined by the Belgian company Ablynx ${ }^{\circledR}$, which refers to the $\mathrm{V}_{\mathrm{H}} \mathrm{H}$ domain from Camelidae species [29, $35,36]$.
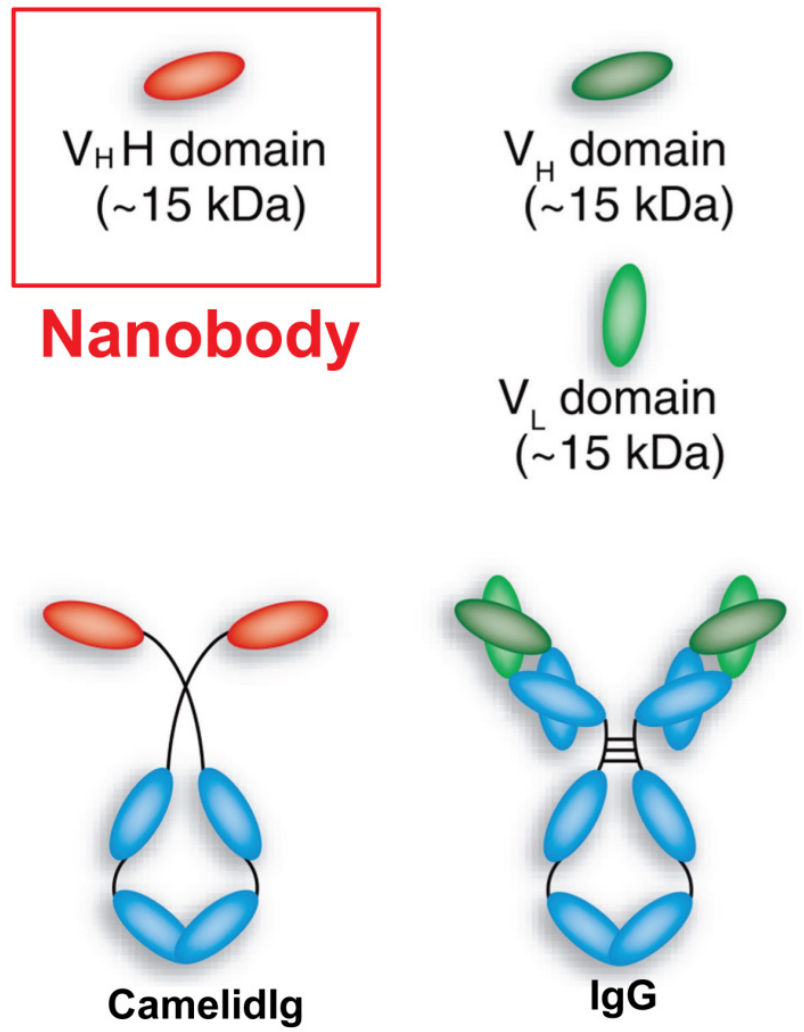

Figure I. A schematic representation of nanobody and antibody domains. Adapted from [26].

Nanobodies are much smaller than common intact antibodies $(\sim 150 \mathrm{kDa})$, as well as their fragments such as Fab ( $\sim 50 \mathrm{kDa})$ and scFv ( $25 \mathrm{kDa})$ [29, 34-36]. The size reduction of an antibody into a nanobody (and the concomitant reduction in valency from bivalent to monovalent) can cause a dramatic change in biological activity, which provides many advantages over conventional antibodies and their recombinant fragments. Firstly, nanobodies are weakly immunogenic in humans because the genes encoding them share high degree of identity with the human type 3 $\mathrm{VH}$ domain $\left(\mathrm{VH}_{3}\right)$ [34]. To aid the clinical translation of nanobodies, further reduction in their immunogenic potential was achieved by Ablynx ${ }^{\circledR}$ via humanization of the nanobodies [37, 38]. Humanization of nanobodies has been described in detail by Vincke et al [39]. Secondly, nanobodies are easy to clone as they consist of only one domain and can therefore be expressed with high yield [40]. Thirdly, nanobodies rapidly and specifically bind tumor antigens, whereas 
the unbound ones are rapidly cleared from the blood mostly by renal elimination [34, 37, 41-44]. Therefore, high tumor-to-background ratios can be obtained as early as $1 \mathrm{~h}$ after tracer injection [29, 42, 45, 46]. Nanobodies also demonstrate high solubility and refolding capacity (stability) even on exposure to extreme conditions such as very low/high $\mathrm{pH}$ and temperature [47]. Lastly, the high variability of length and sequence of $\mathrm{V}_{\mathrm{H}} \mathrm{Hs}$ and the small size allows nanobodies to efficiently enter into tissues and bind epitopes that typically cannot be reached by conventional intact antibodies [34, 37]. The CDRs of the nanobodies play a critical role in their stability and binding affinity $[29,48-51]$. The $\mathrm{V}_{\mathrm{H}} \mathrm{Hs}$ possess an additional disulfide bridge linking the CDRs (CDR1 and CDR3) which enables formation of a new kind of loop that helps in recognizing an increased variety of epitopes [29, 48, 50,51]. In contrast, the binding interfaces of intact antibodies are more flat and less flexible [29, 52], thereby limiting their interactions only on the surface of the antigens. A longer CDR3 in nanobodies also helps them to bind to unique epitopes.

However, the small size of nanobodies can sometimes be disadvantageous. The binding properties of nanobodies might be altered when conjugated with imaging labels such as fluorophores, although there are certain strategies available to address this issue [53]. Also, high uptake of radiolabeled nanobodies in kidneys and liver has been observed in certain cases which not only makes detection of lesions closer to these organs difficult but also results in unwanted dose to these organs $[54,55]$. Rapid clearance of nanobodies may prevent optimum binding to all the epitopes at the disease site, resulting in reduced uptake compared to conventional antibodies. Such rapid clearance of nanobodies from the bloodstream through renal excretion may also hamper their potential for immunotherapy [29]. Many therapeutic applications require a low drug clearance rate to avoid high doses and frequent administration of the therapeutic moiety. The half-lives of nanobodies could be prolonged by fusion of a target specific nanobody unit to a unit binding to albumin [56, 57]. Even though significant increase in half-life could be achieved by this approach, the efficacy of nanobodies in immunotherapy is much less than that of conventional antibodies due to absence of effector domains in nanobodies [29]. Therefore, this strategy does not hold any significant advantage over conventional antibody-based immunotherapy. Despite these limitations, the nanobody technology seems very promising for the development of next generation molecular imaging agents, if not for therapeutic applications.

\section{Generation of nanobodies}

Heavy chain antibodies which are devoid of light chains can easily be produced in animals of the Camelidae family [34, 36, 40], among which camels are the most appropriate choice since they exhibit better ratio of heavy chain antibodies to regular antibodies. In reality, llamas are also often used for this purpose as they are easier to raise and breed due to smaller size [34]. Generally, an animal is immunized with appropriate quantity of antigen once a week for several weeks to raise an $\mathrm{H} 2$-type antibody response. The $\mathrm{V}_{\mathrm{H}} \mathrm{H}$ gene fragments from lymphocytes are amplified by standard molecular biology techniques such as reverse transcription followed by polymerase chain reaction (RT-PCR), ligated in phage display vectors and transformed in bacteria to construct an immune $\mathrm{V}_{\mathrm{H}} \mathrm{H}$ library [26, 29, 34, 37, 58, 59]. Sometimes it is essential to generate $\mathrm{V}_{\mathrm{H}} \mathrm{Hs}$ that are cross-reactive for both human and rodent analogs of the target antigen in order to facilitate pre-clinical testing prior to clinical translation [34, 40]. When a library of appropriate size is obtained, antigen-binding $\mathrm{V}_{\mathrm{H}} \mathrm{H}$ fragments are selected from the library. Selection of nanobodies involves enrichment of antigen-specific binders from immune or naive libraries by phage display, bacterial two-hybrid or bacterial surface display, and subsequent screening for individual colonies from enriched phage populations by enzyme-linked immune sorbent assay (ELISA) [37]. The detailed procedures for these processes have been well-documented in the literature and will not be discussed here [34, 37, 40]. In the following sections, we will discuss the innovative applications of nanobodies as potential next-generation molecular imaging agents.

\section{Molecular imaging with nanobodies}

Nanobodies fulfill most of the requisites of an ideal probe for successful molecular imaging. Owing to their small molecular size, they can easily reach their targets within a few hours post-injection and exhibit great potential in tumor detection, confirmation of target expression, and selection of patients who have the highest chance to benefit from targeted therapies. Several imaging techniques such as SPECT, PET, optical imaging and ultrasound have been successfully employed for molecular imaging using nanobodies (Table 1), with the majority using radionuclide-based techniques (i.e. SPECT and PET) since these techniques are sensitive, quantitative, and clinically relevant [60, 61]. SPECT and PET have the sensitivity needed to visualize most interactions between physiological targets and ligands, which can enable non-invasive detection down to the picomolar level. However, we would like to emphasize that the choice 
of a particular modality primarily depends on the specific query to be addressed through molecular imaging.

For SPECT imaging, the nanobody needs to be labeled with a suitable $\gamma$-emitting radionuclide (e.g. ${ }^{99 \mathrm{mTc}}$ or $\left.{ }^{111} \mathrm{In}\right)$, having an ideal $\gamma$-energy of $100-250$ $\mathrm{keV}$ [60]. These $\gamma$-rays are recorded by the detectors of a dedicated $\gamma$-camera or SPECT instrument, which can be converted into an image upon signal processing to pinpoint the localization of the radiolabeled nanobody. On the other hand, PET requires radiolabeling of the nanobody with a suitable positron-emitting radionuclide (e.g. ${ }^{18} \mathrm{~F},{ }^{64} \mathrm{Cu},{ }^{68} \mathrm{Ga}$ or ${ }^{89} \mathrm{Zr}$ ) [61]. Compared with SPECT, PET has greater advantages with respect to sensitivity and resolution hence has been gaining significantly more clinical popularity over the last decade [61-63]. However, most of the literature reports on radionuclide-based imaging with nano- bodies have used ${ }^{99 \mathrm{~m} T c}$ for SPECT imaging (Table 1). The widespread interest in the use of ${ }^{99 \mathrm{~m} T c}$ is primarily due to its excellent nuclear decay characteristics, viable coordination chemistry for radiolabeling a wide variety of biomolecules and convenient availability from cost-effective ${ }^{99} \mathrm{Mo} /{ }^{99 \mathrm{~m} T c}$ generators [64]. Also, due to the presence of the hexahistidine tag on the nanobody, it can easily be radiolabeled with $99 \mathrm{~m} \mathrm{Tc}(\mathrm{CO})_{3}$ without any chemical modification of the protein [42]. However, the hexahistidine tag on the nanobody poses some concerns as it might reduce immune responses and thus, the necessity for its removal has also been suggested [41]. The high operational cost of on-site cyclotrons needed for production of PET isotopes might be a deterrent for their use, which could be overcome with the use of ${ }^{68} \mathrm{Ga}$ derived from ${ }^{68} \mathrm{Ge} /{ }^{68} \mathrm{Ga}$ generators [41, 65].

Table I: Overview of nanobodies based probes in pre-clinical molecular imaging

\begin{tabular}{|c|c|c|c|c|c|}
\hline Target & Nanobody & $\begin{array}{l}\text { Imaging modality } \\
\text { (label) }\end{array}$ & $\begin{array}{l}\text { Maximum \%ID/g } \\
\text { in the tumor }\end{array}$ & Disease model & References \\
\hline \multirow[t]{5}{*}{ EGFR } & $8 \mathrm{~B} 6$ & $\begin{array}{l}\text { SPECT } \\
(99 \mathrm{mTc})\end{array}$ & $\sim 5$ & $\begin{array}{l}\text { Human epidermoid carcinoma (A431), human prostate } \\
\text { carcinoma (DU145) }\end{array}$ & [42] \\
\hline & 7C12 & 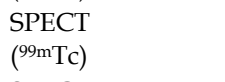 & $\sim 4.5$ & Human epidermoid carcinoma (A431) & {$[43,81,82]$} \\
\hline & 7D12 & $\begin{array}{l}\text { SPECT } \\
\left({ }^{99 \mathrm{mTc})}\right.\end{array}$ & $\sim 4.5$ & Human epidermoid carcinoma (A431) & {$[44,45,81]$} \\
\hline & & $\begin{array}{l}\text { PET } \\
\left({ }^{68} \mathrm{Ga}\right)\end{array}$ & $\sim 7$ & & \\
\hline & & $\begin{array}{l}\text { Optical } \\
\text { (IRDye800CW) }\end{array}$ & $\sim 17$ & & \\
\hline \multirow[t]{3}{*}{ HER-2 } & 2Rs15d & $\begin{array}{l}\text { SPECT } \\
\left({ }^{99 \mathrm{mTC})}\right.\end{array}$ & $\sim 4$ & $\begin{array}{l}\text { Human colon carcinoma (LS174T), human breast cancer } \\
\text { (SKBR3), human ovarian cancer (SKOV3) }\end{array}$ & [59] \\
\hline & 2Rs15d & $\begin{array}{l}\mathrm{PET} \\
\left({ }^{68} \mathrm{Ga}\right)\end{array}$ & $\sim 4$ & Human ovarian cancer (SKOV3) & [41] \\
\hline & $11 \mathrm{~A} 4$ & $\begin{array}{l}\text { Optical } \\
\text { (IRDye800CW) }\end{array}$ & $\sim 2$ & Human breast cancer (SKBR3) & [53] \\
\hline HGF & $1 \mathrm{E} 2$ and $6 \mathrm{E} 10$ & $\begin{array}{l}\text { PET } \\
\left({ }^{89} \mathrm{Zr}\right)\end{array}$ & $\sim 9$ & Human glioblastoma (U87 MG) & [56] \\
\hline \multirow[t]{2}{*}{ MMR } & a-MMR & $\begin{array}{l}\text { SPECT } \\
\left({ }^{9} \mathrm{mTc}\right)\end{array}$ & $\sim 3$ & $\begin{array}{l}\text { Mammary adenocarcinoma (TS/A), Lewis lung carci- } \\
\text { noma (3LL-R) }\end{array}$ & [54] \\
\hline & & $\begin{array}{l}\text { SPECT } \\
\left({ }^{99 \mathrm{~m} T \mathrm{C})}\right.\end{array}$ & $\sim 5$ & Rheumatoid arthritis & [95] \\
\hline \multirow[t]{2}{*}{ VCAM-1 } & cAbVCAM1-5 & $\begin{array}{l}\text { SPECT } \\
(99 \mathrm{mTc})\end{array}$ & $\sim 3$ & $\begin{array}{l}\text { Atherosclerosis } \\
\text { (ApoE-deficient mice) }\end{array}$ & [101] \\
\hline & & $\begin{array}{l}\text { Ultrasound } \\
\text { (microbubble) }\end{array}$ & NA & Murine adenocarcinoma (MC38) & [77] \\
\hline CEA & CEA1 & 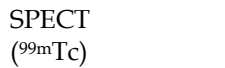 & $\sim 3$ & Human colon adenocarcinoma (LS174) & [55] \\
\hline
\end{tabular}

NA: Not applicable

Optical imaging is an emerging technology that has also been employed for cancer imaging using nanobodies, after a suitable fluorophore is conjugated [66]. The recent development in near-infrared (NIR, $700-900 \mathrm{~nm}$ ) fluorophores have made this imaging modality highly flexible, sensitive, fast and cost-effective [66, 67]. The major advantage of optical imaging is that it is simple to set up and does not require dedicated facilities. On the other hand, due to scattering and absorption of light in tissues, optical imaging phenomenon has a relatively small depth of penetration ranging from hundreds of microns to several centimeters, depending on the approach [68, 69]. Thus, while optical imaging is well suited to study surface lesions in pre-clinical studies, it cannot currently be used for whole-body imaging. The use of biomedical optoacoustics as a powerful tool for high-resolution visualization of optical contrast has 
recently been proposed in order to overcome the limitations imposed by light scattering in deep tissues [70]. However, this approach is still in its infancy and extensive research efforts would be required to determine its suitability for this purpose. In clinical context, application of optical imaging for image-guided surgery has a bright future and allows imaging of several kinds of tumors during surgery which are otherwise difficult to locate [71, 72].

Ultrasound is a safe, fast, and inexpensive technique widely used in the clinic for medical diagnosis [73]. This imaging technique makes use of sound waves (typically with frequencies in the range of 1 to $40 \mathrm{MHz}$ ) which are reflected differently by different organs and tissues. When compared to other imaging modalities described above, the image quality in ultrasound is often inferior as blood is a poor scatterer of ultrasound waves at clinical diagnostic transmission frequencies [73]. Microbubbles $(\mu \mathrm{B})$ are generally used to enhance contrast in ultrasound imaging due to their superior scattering properties and their dynamic response to the application of an ultrasonic field [74]. Sometimes, intraoperative ultrasound imaging is used during surgical procedures [73, 75, 76]. Recently, nanobody-based ultrasound imaging has been reported [77]. However, this approach is still in its infancy and extensive studies will be needed before it can be translated to clinical settings.

As an intriguing platform, nanobodies have been proposed as potential molecular imaging agents not only in oncology but also for monitoring and quantifying arthritis, atherosclerosis and other inflammatory diseases [29, 30, 37]. Various regulatory proteins and/or receptors are overexpressed in certain diseases, which represent the molecular basis for imaging using nanobody-based probes, most of which are summarized in the following text.

\section{Imaging of the epidermal growth factor receptor}

Epidermal growth factor receptor (EGFR; also called HER-1) is a member of the HER-kinase family, together with HER-2, HER-3, and HER-4 [78, 79]. EGFR is overexpressed in a variety of human tumors including non-small cell lung cancer, breast, head and neck, gastric, colorectal, esophageal, prostate, bladder, renal, pancreatic, and ovarian cancers [78]. Activation of EGFR causes signaling that may lead to cell division, increased motility, angiogenesis and decreased apoptosis [80]. These effects are mediated by a complex series of signaling mechanisms, such as engagement of the mitogen-activated protein kinase (MAPK) and phosphatidylinositol-3 kinase (PI3K) pathways [78, 80]. Conventionally, immunohistochemical staining of tumor biopsies is used for assessing EGFR overexpression. However, it is more advantageous to measure EGFR expression using molecular imaging approach since it is non-invasive and can assess heterogeneity of both the primary tumor and the metastases. In addition, non-invasive imaging of EGFR expression can be repeated multiple times during the course of the disease and/or therapeutic intervention to provide biological insights and improve patient management.

SPECT imaging of EGFR expression using an anti-EGFR nanobody as the targeting agent was first reported by Huang et al. [42]. The nanobody (8B6) was radiolabeled through its C-terminal hexahistidine-tag with 99mTc-tricarbonyl intermediate $\left[{ }^{99 \mathrm{~m} T c}\left(\mathrm{H}_{2} \mathrm{O}\right)_{3}(\mathrm{CO})_{3}\right]$. The hexahistidine tag on the $\mathrm{C}$-terminal of the nanobodyenables easy radiolabeleing with ${ }^{9} \mathrm{~m} \mathrm{Tc}\left(\mathrm{H}_{2} \mathrm{O}\right)_{3}(\mathrm{CO})_{3}$ without any additional chemical modification. Therefore, this facile approach based on ${ }^{99 \mathrm{~m} T c}(\mathrm{I})$-tricarbonyl chemistry is the preferred method for radiolabeling nanobodies with 99mTc. The radiolabeled nanobody demonstrated high specificity and selectivity towards EGFR-expressing cells. Tracer clearance was mainly via renal excretion and it was relatively fast (with a half-life of $1.5 \mathrm{~h}$ ) [42]. SPECT imaging studies showed that it was possible to differentiate between tumors with high and moderate EGFR expression. In another study, the in vivo tumor uptake and biodistribution of two ${ }^{99 \mathrm{~m} T c-l a b e l e d ~ a n-~}$ ti-EGFR nanobodies (7C12 and 7D12) was compared using pinhole SPECT/CT (Figure 2) [81]. It was found that binding of both the tracers was EGFR specific. In addition, high tumor uptake with low liver uptake, and rapid blood clearance were observed in both cases. However, in addition to rapid renal clearance, retention of the radiolabeled nanobodies in the kidneys was also observed which might be a cause of concern as it may lead to unwanted renal toxicity. In order to understand this phenomenon of renal toxicity, the role of megalin (an endocytic receptor which is highly expressed in renal proximal tubule) on the renal uptake of anti-EGFR ${ }^{99 m T c-7 C 12 ~ n a n o b o d y ~ w a s ~}$ evaluated in a related study [43]. It was concluded that megalin contributed to the renal accumulation of 99mTc-7C12. This was confirmed by the ability of gelofusine and/or lysine, known inhibitors of megalin, to reduce renal uptake of $99 \mathrm{mTc}-7 \mathrm{C} 12$. Co-injection of gelofusine and/or lysine with the tracer lowered the renal uptake and increased the tumor uptake. This procedure serves not only to allay the concerns regarding renal toxicity associated with nanobodies, but also sets an example for optimization of nuclear imaging protocols using nanobodies for further clinical studies. In another report, it was further demonstrated that tumor uptake of $99 \mathrm{~m} \mathrm{Tc}-7 \mathrm{C} 12$ was correlated with tumor burden [82]. This was confirmed by 
reduction of $99 \mathrm{~m}$ Tc-7C12 uptake upon Erlotinib (EGFR inhibitor) therapy. The authors suggested that quantification of $99 \mathrm{mTc}-7 \mathrm{C} 12$ uptake would be helpful in monitoring the therapy response of EGFR expressing tumors.

Vosjan et al. reported PET imaging of EGFR expression using 7D12 nanobody [44]. The nanobody was conjugated with p-isothiocyanatobenzyldesferrioxamine (Df-Bz-NCS) and radiolabeled with ${ }^{68} \mathrm{Ga}$. The short half-life of ${ }^{68} \mathrm{Ga}\left(\mathrm{t}_{1 / 2}=68 \mathrm{~min}\right)$ is apt for radiolabeling nanobodies which demonstrate a fast in vivo pharmacokinetics. The biodistribution studies revealed high tumor uptake in EGFR-positive tumors and high tumor-to-blood ratio within $1 \mathrm{~h}$ post-injection. Tumors could be clearly visualized by PET imaging, and the results were comparable with that of SPECT using the same nanobody [81]. In another study by Oliveira et al, optical imaging of EGFR using 7D12 nanobody conjugated with the NIR dye IRDye800CW was reported [45]. Again, rapid visualization of the tumor (within 30 min post-injection) was observed. Also, the tumor uptake observed here ( $17 \% \mathrm{ID} / \mathrm{g}$ ) was much higher than what was ob-

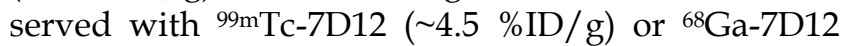
( $\sim 7 \% \mathrm{ID} / \mathrm{g})$ (Table 1). The significant difference in tumor uptake might be attributed to the differences in the conjugation efficiency and the nature of the fluorophore. Owing to its rapid accumulation into the tumor and the high tumor to background ratios that could be achieved, this optical probe holds promise for use in image-guided surgery.

\section{Imaging of the human epidermal growth factor receptor 2}

The human epidermal growth factor receptor type 2 (HER-2 or CD340) is another member of the HER-kinase family that is overexpressed in various tumor types such as breast, ovarian, prostatic, and colorectal cancer $[79,83,84]$. HER-2 is a transmem-

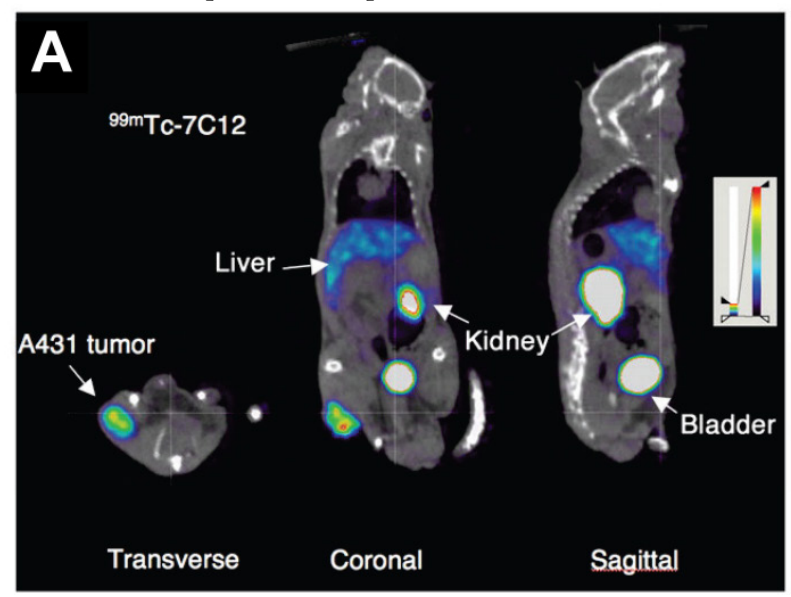

brane glycoprotein consisting of three domains: extracellular (N-terminal), transmembrane (single alpha-helix), and intracellular (tyrosine kinase).

The generation of a large number of anti-HER-2 nanobodies for non-invasive imaging of HER-2 expression was reported by Vaneycken et al. [59]. The authors could identify 38 different nanobodies that could target HER-2 expression, out of which the nanobody 2Rs15dHis6 was selected as lead compound for further development as a clinical molecular imaging agent. The nanobody was radiolabeled with 99mTc adopting the procedure described earlier in the review. SPECT imaging and biodistribution studies showed high uptake of ${ }^{99 m}$ Tc-labeled 2Rs15dHis6 in HER-2 positive tumors, fast blood clearance, low accumulation in non-target organs (except kidneys which are responsible for tracer clearance), and high concomitant tumor-to-blood and tumor-to-muscle ratios at $1 \mathrm{~h}$ post-injection (Figure 3A). Recently, PET imaging of HER-2 expression using 2Rs15d nanobody was reported by the same group [41]. The hexahistidine tag from the lead compound reported earlier [59] was removed in order to reduce the risk of immunogenicity and the non-tagged format was produced. The nanobody could be radiolabeled with ${ }^{68} \mathrm{Ga}$ after conjugation with the bifunctional chelator, p-isothiocyanatobenzyl-1,4,7-triazacyclononane-1,4,7triacetic acid (p-SCN-Bz-NOTA). Similar as that observed in the previous study [59], biodistribution and PET/CT studies revealed high tumor uptake, high tumor-to-blood and tumor-to-muscle ratios as early as $1 \mathrm{~h}$ post-injection, resulting in high-contrast PET/CT images (Figure 3B). On the basis of mouse toxicity and dosimetry studies, the radiotracer was found to be safe and the authors claimed that ${ }^{68} \mathrm{Ga}-\mathrm{NOTA}-2 \mathrm{R} s 15 \mathrm{~d}$ was ready for first-in-human clinical trials.

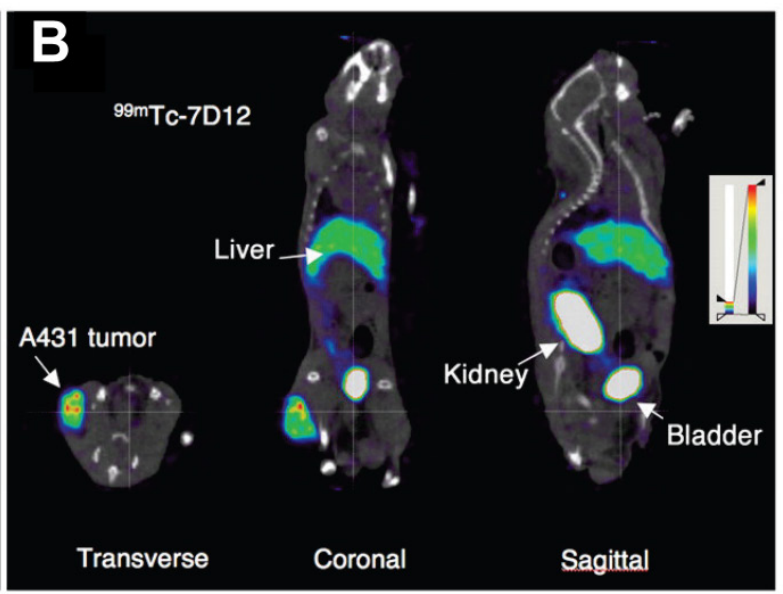

Figure 2. Nanobody-based imaging of EGFR expression. Transverse, coronal, and sagittal views of SPECT/CT images of mice bearing A43I tumor injected with 99mTc-7CI2 (A) or $99 \mathrm{mTc}-7 D 12$ (B). Images were acquired at I h after injection. Adapted from [8I]. 
Pruszynski et al. reported the radiolabeling of another anti-HER-2 nanobody (5F7GGC) with 125/131I using the residualizing agent, $\mathrm{N}^{\varepsilon}-\left(3-\left[{ }^{131} \mathrm{I}\right]\right.$ iodobenzoyl) -Lys ${ }^{5}-\mathrm{N}^{\alpha}$-maleimido-Gly ${ }^{1}$-GEEEK [85]. The residualizing agent contains multiple negatively charged D-amino acids and is effective in enhancing the retention of radioactivity in tumor cells after receptor mediated internalization of the radiolabeled nanobody. The potential of this radiotracer for targeting breast cancer was demonstrated, which could be extended for future SPECT and PET imaging of HER-2 expression in cancer patients using ${ }^{123}$ I and ${ }^{124}$ I, respectively. In another study, rapid optical imaging of human breast cancer xenografts with high tumor-to-background ratios (Figure 3C) was reported using anti-HER-2 nanobody (11A4) conjugated to IRDye $800 \mathrm{CW}$ [53]. Under the guidance of the real-time fluorescent images obtained from the camera using 11A4-IR probe, surgical resection of a HER-2-positive xenograft from a mouse could be demonstrated. Both tumor and kidney were clearly visible through the skin during the operation. This was the first study where image-guided surgery was successfully carried out using nanobody-based optical imaging probe. Further development of this method would help in precise and rapid identification of HER-2 positive tumors, allow assessment of response to HER-2 therapies and might assist in image-guided surgeries if required. The first clinical trial with a nanobody-based molecular imaging tracer targeting HER-2 is currently ongoing (EudraCT 2012-001135-31) and the results are yet to be reported [33].

\section{Imaging of the hepatocyte growth factor}

Hepatocyte growth factor (HGF), also known as scatter factor, is a paracrine cellular growth, motility and morphogenic factor [86]. Secreted by mesenchymal cells as a single-chain inactive polypeptide, HGF acts as a multifunctional cytokine on cells of mainly epithelial and endothelial origin, as well as on hematopoietic progenitor cells. HGF is the only known ligand for c-Met, a membrane receptor that is essential for embryonic development and is expressed on the epithelial cells of many organs such as liver, prostate, pancreas, muscle, kidney, and bone marrow [87]. In tumor cells, c-Met activation triggers diverse series of signaling cascades resulting in cell growth, proliferation, invasion, metastasis, and escape from apoptosis [86-88]. Elevated levels of HGF and c-Met have been observed in most solid tumors and are associated with increased aggressiveness of tumors and poor prognostic outcome of cancer patients [86-88].

The potential of nanobodies for PET imaging and therapy of HGF-expressing tumors was reported by Vosjan et al. [56]. Two nanobodies (1E2 and 6E10) were each molecularly fused to albumin-binding units (Alb8) to obtain serum half-life extension, conjugated with Df-Bz-NCS chelator and radiolabeled with ${ }^{89} \mathrm{Zr}$, with the goals of preventing the binding of HGF to c-Met receptor and assess the use of these novel tracers in cancer diagnosis and therapy [56, 89]. Although biodistribution studies in nude mice showed high uptake in xenograft U87 MG glioblastoma tumors (> 7 $\% \mathrm{ID} / \mathrm{g}$ ), blood clearance of the tracers was very slow due to fusion of nanobodies with albumin units and no PET imaging data was reported.
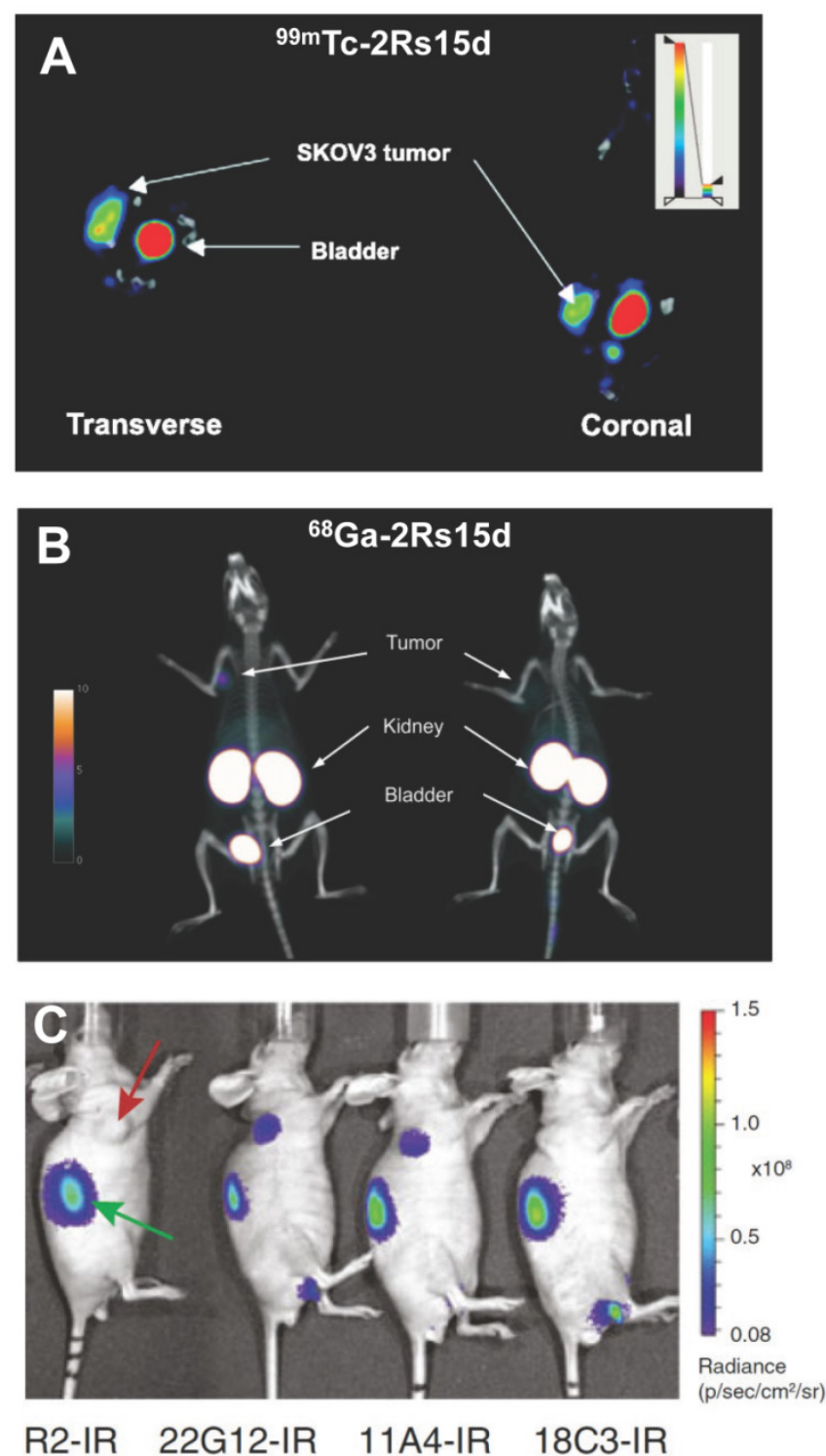

Figure 3. Nanobody-based imaging of HER-2 expression. (A) Transverse and coronal views of SPECT/CT images of HER-2 positive SKOV3 tumor-bearing mice at I h post-injection of $99 \mathrm{mTc}-2 \mathrm{Rs} / 5 \mathrm{~d}$. (B) PET/CT images of rats bearing SKOV3 (left) or HER-2 negative MDA-MB-435D (right) tumor xenografts at I $h$ post-injection of ${ }^{68} \mathrm{Ga}-2 \mathrm{Rs} / 5 \mathrm{~d}$. (C) In vivo optical imaging of SKBR3 tumor-bearing mice at $4 \mathrm{~h}$ post-injection of HER-2 specific (IIA4, 18C3 or $22 \mathrm{GI}$ ) or negative control (R2) nanobodies conjugated to IRDye800CW (abbreviated as IR). Tumors are indicated with red arrow and kidneys with green arrow. Adapted from $[41,53,59]$. 
In this study, the therapeutic potential of these nanobodies was also evaluated in the same animal model [56]. All the mice treated with the nanobodies exhibited delayed tumor growth when compared with the control group that was injected with saline, and no toxicity to normal organs was observed. Taken together, although the therapeutic efficacy of albumin fused anti-HGF nanobodies was demonstrated, the nanobodies without fusion to albumin seem to be the better choice for molecular imaging applications because of their rapid blood clearance and fast tumor accumulation.

\section{Imaging of the macrophage mannose receptor}

The macrophage mannose receptor (MMR) is a transmembrane glycoprotein that is expressed on macrophages [90], which is primarily responsible for endocytic clearance of certain glycoproteins and phagocytosis of unopsonized microorganisms. It has been reported that certain components of the tumor stroma, especially in the hypoxic areas, that are highly pro-angiogenic overexpress MMR, which plays an important role during tumor growth and related biological processes such as angiogenesis, metastasis, and immune suppression [91]. Therefore, MMR is an attractive marker for non-invasive molecular imaging of tumor-associated macrophages.

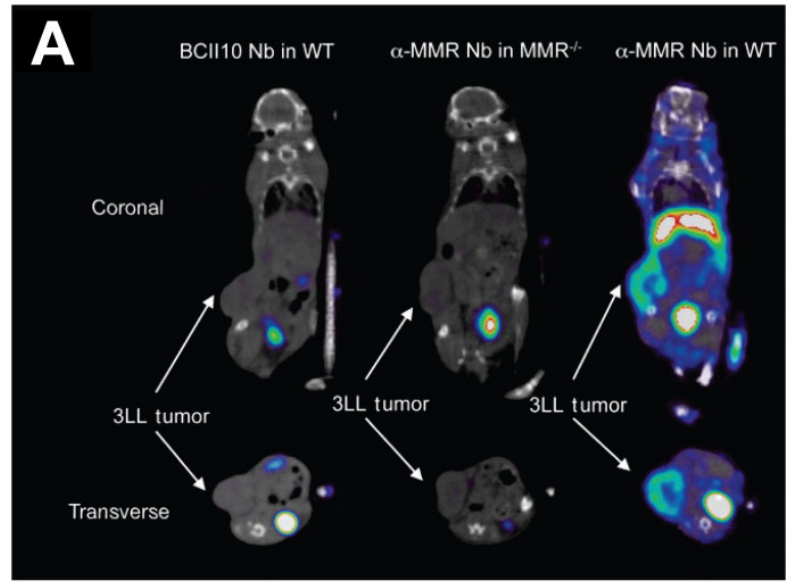

Figure 4. Nanobody-based imaging of MMR expression. (A) Coronal and transverse views of SPECT/CT images of 3LL tumor-bearing wide-type (WT) or MMR knockout (MMR-/-) mice at $3 \mathrm{~h}$ post-injection of $99 \mathrm{mTc}$-labeled BClll0 control nanobody (Nb) or anti-MMR (a-MMR) nanobody. (B) SPECT/CT images of mice showing signs of arthritis in both hind limbs at $3 \mathrm{~h}$ post-injection of $99 \mathrm{mT}$ c-labeled a-MMR nanobody or BCIII0 control nanobody. Tracer accumulation of 99mTc-labeled a-MMR nanobody was evident in knees, ankles, and metatarsal joints (indicated by arrows), but not the control nanobody. Adapted from [54, 95].

Interestingly, MMR was also found to be involved in the formation of multinucleated osteoclasts, by binding to terminal high-mannose-type oligosaccharides expressed on osteoclast precursor cells [92, 93]. Osteoclasts, derived from monocyte or macrophage lineage, are a type of bone cells involved in bone resorption, which degrade the bone tissue by removing its mineralized matrix and breaking up the organic bone. Therefore, they are also responsible for the progressive destruction of bone tissue in rheu-
Anti-MMR nanobodies were developed and successfully used for SPECT/CT imaging of tumor-infiltrating macrophages [54]. The nanobodies were radiolabeled with $99 \mathrm{mTc}$ and injected in mammary adenocarcinoma and Lewis lung carcinoma (TS/A and 3LL-R) tumor-bearing mice. Biodistribution studies and pinhole SPECT/CT imaging showed rapid targeting of MMR expressing cells in tissues, with high tumor-to-background ratio (Figure 4A). Tumor retention of the radiolabeled nanobody was target-specific and absent in MMR knockout mice. However, in both the TS/A and 3LL-R models, 99mTc-labeled anti-MMR nanobody accumulated to a higher extent in the liver and spleen (due to the presence of MMR expression in these organs) than the tumor, which could be minimized by co-injection of excess unlabeled, bivalent anti-MMR nanobody without compromising tumor uptake [54] . The authors suggested that this strategy of co-injecting bivalent cold anti-MMR nanobody to reduce extratumoral tracer uptake would help in clinical translation of this radiotracer. In such a strategy, bivalent cold nanobodies would be efficient at binding non tumor sites and thus reducing non specific signals. The large size of the bivalent nanobody prevents its penetration into the tumor leaving the tumor targeting sites free for the labeled monovalent nanobodies.

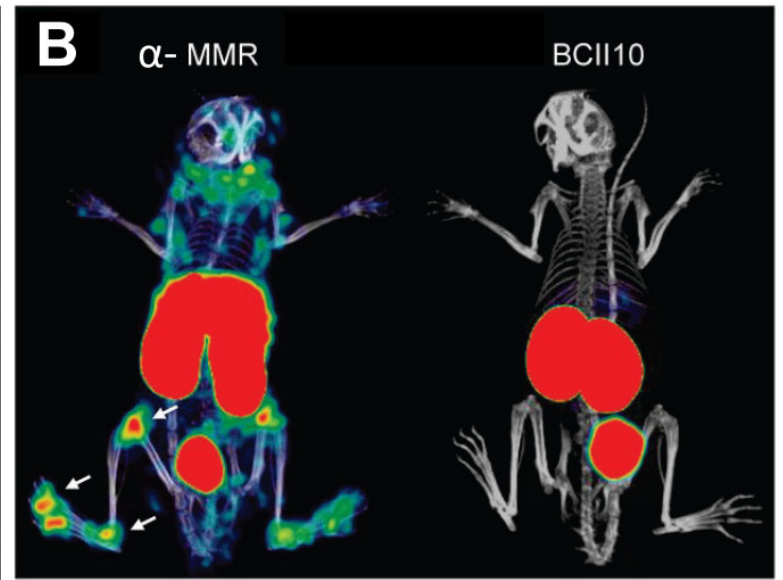


inflamed joints of arthritic mice (Figure 4B). With further research efforts, this approach might prove to be a useful tool for monitoring and quantifying joint inflammation in rheumatoid arthritis patients.

\section{Imaging of the vascular cell adhesion molecule-I}

Vascular cell adhesion molecule-1 (VCAM-1), also known as cluster of differentiation 106 (CD106), is a protein that is encoded by the VCAM-1 gene in humans [96]. The VCAM-1 protein mediates the adhesion of lymphocytes, monocytes, eosinophils, and basophils to vascular endothelium and also functions in leukocyte-endothelial cell signal transduction. VCAM-1 is expressed at low levels in non-atherosclerotic arteries. However, hypercholesterolemia rapidly induces VCAM-1 expression by endothelial cells in regions prone to atheroma formation [97, 98]. It has been reported that arterial muscle cells and even macrophages can express VCAM-1 in hypercholesterolemic animals [99]. In vitro, pro-inflammatory cytokines readily augment the expression of VCAM-1 in endothelial cells and other cell types relevant to atherosclerosis $[99,100]$. VCAM-1 binds to very late antigen-4 (VLA4) present on the surface of leukocytes. Generally, active inflammation characterized by leukocyte infiltration is recognized as a major criterion for defining vulnerable plaques [99]. Therefore, VCAM-1 is a highly relevant molecular target for non-invasive detection of such lesions.

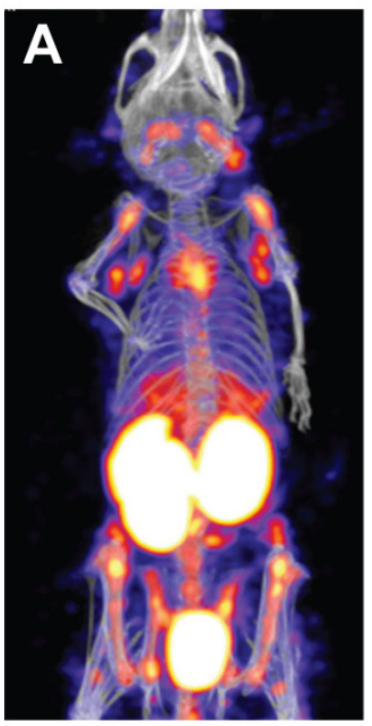

99mTc-cAbVCAM1-5

(No competition)

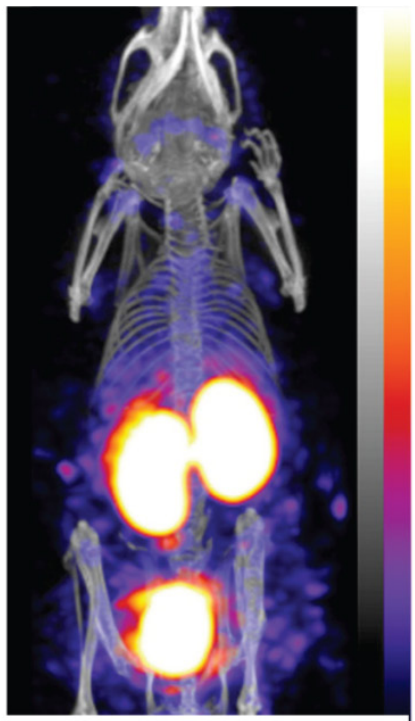

99mTc-cAbVCAM1-5 + excess cAbVCAM1-1

(Competition)
Preclinical imaging of atherosclerotic plaques using anti-VCAM-1 nanobodies was reported by Broisat et al. [101]. The nanobodies were radiolabeled with ${ }^{99 \mathrm{mTc}}$ for SPECT imaging of atherosclerotic lesions in ApoE-deficient mice [101, 102]. Among the various nanobodies studied, cAbVCAM1-5 was cross-reactive for human VCAM-1 and exhibited high lesion-to-control, lesion-to-heart, and lesion-to-blood ratios. Uptake of 99mTc-cAbVCAM1-5 in atherosclerotic lesions could be readily visualized in ApoE-deficient mice, while no tracer uptake was observed in the control animals or with the non-targeting control nanobody (cAbBcII10). Co-injection of a 100-fold excess of unlabeled competitor cAbVCAM1-1 (a nanobody recognizing the same VCAM-1-epitope as cAbVCAM1-5) with 99mTc-cAbVCAM1-5 resulted in significant decrease in 99mTc-cAbVCAM1-5 uptake in the liver, lymphoid tissues, and atherosclerotic lesions, thereby demonstrating specificity of the radiolabeled nanobody (Figure 5A). The uptake of 99mTc-cAbVCAM1-5 in VCAM-1-positive lesions was further confirmed by autoradiography and immunohistochemistry. Though this study successfully demonstrated the prospective of radiolabeled nanobodies as tracers in nuclear cardiology for the first time, several pertinent factors such as immunogenicity, toxicity and safety need to be evaluated before such tracers can actually be translated to clinical settings.

Figure 5. Nanobody-based imaging of VCAM-I expression. (A) SPECT/CT images of atherosclerotic lesions in ApoE-deficient mice injected with 99mTc-cAbVCAMI-5 alone (no competition) or with a 100 -fold excess of unlabeled cAbVCAMI-I (competition). Competition resulted in significant decrease of tracer uptake in the liver, lymphoid tissues, and atherosclerotic lesions, thereby demonstrating VCAM-I specificity. (B) Transverse B-mode ultrasound images of MC38 tumors overlaid with contrast-enhanced signal at 10 min post-injection of either $\mu$ B-cAbVCAMI-5 or a non-targeting control $\mu B-c A b G F P$. Adapted from [77, I0I]. 
Recently, the same group investigated the suitability of anti-VCAM-1 nanobodies for ultrasound imaging of VCAM-1 expression in MC38 murine tumor model [77]. The nanobodies were conjugated to the surface of microbubbles through biotin-streptavidin interaction. Contrast-enhanced ultrasound imaging using $\mu \mathrm{B}-\mathrm{cAbVCAM} 1-5$ showed enhanced echo signal intensity in the tumor compared to control microbubbles, within $10 \mathrm{~min}$ after injection (Figure 5B). After bursting of the microbubbles, the signal almost completely disappeared, indicating that the majority of unbound circulating microbubbles had cleared from the bloodstream. Overall, this preliminary study showed that nanobody-based molecular ultrasound holds the potential for rapid and cost-effective in vivo detection of VCAM-1 expression in the tumor vasculature.

\section{Imaging of the carcinoembryonic antigen}

Carcinoembryonic antigen (CEA) is a complex and highly glycosylated macromolecule which is normally produced in gastrointestinal tissue during fetal development [103]. Although usually present at very low levels in healthy adults, CEA is highly expressed in many cancer types such as colorectal carcinoma and adenocarcinomas of the lung, breast, other gastrointestinal organs and the ovaries. Therefore, CEA has been an intensively studied target for cancer diagnosis and therapy over the last several decades [103].

The potential of nanobodies for SPECT imaging of tumor CEA expression was investigated by Cortez-Retamozo et al. [55]. The CEA specific nanobody (CEA1) was radiolabeled with $99 \mathrm{mTc}$. Biodistribution and SPECT imaging studies in mice bearing CEA-positive human colon adenocarcinoma (LS174T) tumor showed both hepatic and renal clearance of the radiolabeled nanobody, resulting in low blood radioactivity levels at $3 \mathrm{~h}$ post-injection with average tumor uptake of $>3 \% \mathrm{ID} / \mathrm{g}$, which showed good contrast between the CEA-positive tumor and the contralateral muscle region. However, a major limitation of this radiotracer is the high liver and kidney uptake, which might make detection of lesions closer to or inside these organs difficult. The liver and kidney uptake can possibly be reduced without reducing the tumor uptake by co-injection of an optimal dose of cold nanobody [54] and excess amount of amino acid such

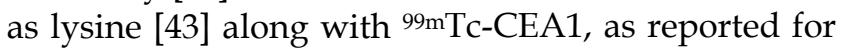
other receptor imaging using nanobodies.

\section{Conclusion and future perspectives}

Molecular imaging is the foundation for accurate diagnosis and pre-treatment staging of various diseases, monitoring the response to therapy and providing surveillance after therapeutic intervention. Recent advances in molecular imaging using nanobody-based probes have enhanced the possibility of high-contrast imaging of different types of tumors within much shorter time period after tracer injection, when compared to the conventional intact antibody based approaches. Nanobodies are smaller than intact antibodies and can penetrate into solid tumor tissue more efficiently, thereby representing a promising class of targeting ligands for non-invasive molecular imaging of specific targets of interest. The maturity in nanobody technology would improve our understanding of the molecular alterations in various types, subtypes and stages of cancers and other diseases, which can help the choice of suitable targeted therapeutics for each individual patient. However, although it has been more than 2 decades since nanobodies were first described, the translation of these promising imaging agents and technologies to the clinic has been very slow. Meanwhile, the development of a new diagnostic probe is an iterative process that requires substantial effort and sometimes luck. The reasons for slow clinical translation is complex and may include considerable regulatory hurdles, limited potential market, lobbying by the manufacturers of other molecular imaging probes, lack of reimbursement strategies for novel imaging agents, etc. Despite these hurdles, the exciting results obtained to date with nanobodies for molecular imaging clearly indicated that these tracers will have multifaceted applications in future clinical practices.

In this review we have described the recent advances in the field of molecular imaging using nanobody-based probes, which provided compelling evidence that these new molecules might be considered as "magic bullets" of molecular imaging in the foreseeable future. Although we have restricted our discussion to molecular imaging applications only, nanobodies may also be the molecules of choice in biotechnology, development of biological sensors and other clinical applications. Primarily, nanobodies have been proposed as efficient probes for oncologic imaging. With further improvement in engineering of various nanobody formats and refinement in conjugation chemistry, they may also be useful for monitoring various other diseases such as amyloidoses, viral infections, cardiac problems, etc. The image-guided surgery approach using nanobody-based optical imaging probes, if successfully translated to clinical settings would assist the surgeons in performing more radical tumor resections with improved cosmesis, thereby improving the management and welfare of cancer patients.

Utilization of nanobodies for targeted therapy has been proposed. However, we believe that the use 
of nanobodies themselves as drugs may not be the best option, due to their rapid clearance from blood, and opine that the conventional antibodies will continue to play a dominant role in immunotherapy. However, nanobodies could play an important role as diagnostic tools in tumor detection, evaluation of target expression before initiating a targeted therapy, prediction or monitoring response to a certain targeted therapy, as well as detection of possible reoccurrence of the disease. Enabling same day imaging of various lesions using nanobody-based probes would accelerate evaluation of patient care and improve patient management. Additionally, various types of nanocarriers, such as iron oxide nanoparticles, silica nanoparticles, copper sulfide nanoparticles, gold nanostructures, carbon nanomaterials, and upconversion nanophosphors can be conjugated with nanobodies for non-invasive visualization of tumors [104-113]. This approach can not only find application in molecular imaging of various types of receptor expressions but also holds promise for simultaneous tumor targeted delivery of anticancer drugs. The high surface area to volume ratio of the nanocarriers enables rich surface chemistry for attachment of nanobodies on their surface while retaining high loading capacity for detection elements and therapeutic payload [114]. The small size of nanobodies can enable the attachment of a large number of nanobodies per nanocarrier, which may lead to significantly enhanced tumor targeting efficiency and specificity. However, nanoparticle usage might be limited by their pharmacokinetics, high liver and spleen uptake that might make visualization of deep seated tumors in proximity to these organs difficult [115]. Also, there might be issues related to toxicity of nanoparticles in certain cases [116, 117].

Most of the applications reported to date using nanobodies have employed SPECT or PET as the imaging modality, though efforts towards the use of other techniques such as optical and ultrasound imaging are also emerging. No single modality is perfect and sufficient to gain all the necessary information and therefore combination of multiple molecular imaging techniques can offer synergistic advantages over any single modality. It should be possible to develop nanobody-based multimodal contrast agents or imaging probes to address this issue in molecular imaging. Such probes would provide much more information than single modality nanobody-based probes that exist in the literature [13]. For example, the synergistic combination of PET and magnetic resonance imaging (MRI) would merge the advantage of high soft tissue contrast of MRI with the functional information of PET, thereby leading to improved diagnostic accuracy and radiotherapy planning. The dual modality molecular imaging agents using optical and MR based probes might be helpful in surgical procedures where optical imaging can be used to guide the scalpel and MR to ensure that all cancerous material has been completely removed. However, direct attachment of multimodal probes with nanobodies might be challenging due to the limited number of conjugation sites available and the potential interference with their receptor binding ability. The use of nanocarriers would be suitable for this purpose as they have large surface areas where multiple functional moieties can be incorporated for multi-modality molecular imaging [106]. With further impetus on development of such advanced probes, nanobody-based multimodality imaging approaches hold the potential to carve a niche for themselves in the clinic.

Overall, the recent preclinical success of nanobodies clearly encourages further research and development efforts incorporating broader application of molecular imaging, eventually in clinical settings. Interdisciplinary and concerted efforts of synthetic chemists, molecular biologists, biomedical and imaging scientists, clinicians, and the regulatory agencies are needed to achieve the ultimate goal of personalized medicine.

\section{Acknowledgements}

This work is supported, in part, by the University of Wisconsin - Madison, the National Institutes of Health (NIBIB/NCI 1R01CA169365), the Department of Defense (W81XWH-11-1-0644), the American Cancer Society (125246-RSG-13-099-01-CCE), and the Fulbright Scholar Program.

\section{Competing Interests}

The authors have declared that no competing interest exists.

\section{References}

1. Cassidy PJ, Radda GK. Molecular imaging perspectives. J R Soc Interface. 2005; 2 : 133-44.

2. Gambhir SS. Molecular imaging of cancer with positron emission tomography. Nat Rev Cancer. 2002; 2: 683-93.

3. Herschman HR. Molecular imaging: looking at problems, seeing solutions. Science. 2003; 302: 605-8.

4. Baum RP, Kulkarni HR. THERANOSTICS: From Molecular Imaging Using Ga-68 Labeled Tracers and PET/CT to Personalized Radionuclide Therapy The Bad Berka Experience. Theranostics. 2012; 2: 437-47.

5. Velikyan I. Molecular imaging and radiotherapy: theranostics for personalized patient management. Theranostics. 2012; 2: 424-6.

6. Weissleder R, Pittet MJ. Imaging in the era of molecular oncology. Nature. 2008; 452: 580-9.

7. Hoffman JM, Gambhir SS. Molecular imaging: the vision and opportunity for radiology in the future. Radiology. 2007; 244: 39-47.

8. Massoud TF, Gambhir SS. Molecular imaging in living subjects: seeing fundamental biological processes in a new light. Genes Dev. 2003; 17: 545-80.

9. Nolting DD, Nickels ML, Guo N, Pham W. Molecular imaging probe development: a chemistry perspective. Am J Nucl Med Mol Imaging. 2012; 2: 273-306.

10. van Dongen GA, Ussi AE, de Man FH, Migliaccio G. EATRIS, a European initiative to boost translational biomedical research. Am J Nucl Med Mol Imaging. 2013; 3: 166-74. 
11. Wu Y, Zhang W, Li J, Zhang Y. Optical imaging of tumor microenvironment. Am J Nucl Med Mol Imaging. 2013; 3: 1-15.

12. Pichler BJ, Wehrl HF, Judenhofer MS. Latest advances in molecular imaging instrumentation. J Nucl Med. 2008; 49 Suppl 2: 5S-23S.

13. Jennings LE, Long NJ. 'Two is better than one'--probes for dual-modality molecular imaging. Chem Commun (Camb). 2009;: 3511-24.

14. Menon JU, Gulaka PK, McKay MA, Geethanath S, Liu L, Kodibagkar VD. Dual-modality, dual-functional nanoprobes for cellular and molecular imaging. Theranostics. 2012; 2: 1199-207.

15. Balyasnikova S, Lofgren J, de Nijs R, Zamogilnaya Y, Hoigaard L, Fischer BM. PET/MR in oncology: an introduction with focus on MR and future perspectives for hybrid imaging. Am J Nucl Med Mol Imaging. 2012; 2: 458-74.

16. Cai $W$, Hong H. In a "nutshell": intrinsically radio-labeled quantum dots. Am J Nucl Med Mol Imaging. 2012; 2: 136-40.

17. Rischpler C, Nekolla SG, Beer AJ. PET/MR imaging of atherosclerosis: initial experience and outlook. Am J Nucl Med Mol Imaging. 2013; 3: 393-6.

18. Wu AM. Engineered antibodies for molecular imaging of cancer. Methods. 2014; 65: 139-47.

19. Reubi JC, Maecke HR. Peptide-based probes for cancer imaging. J Nucl Med. 2008; 49: 1735-8.

20. Zhu L, Guo N, Li Q, Ma Y, Jacboson O, Lee S, et al. Dynamic PET and Optical Imaging and Compartment Modeling using a Dual-labeled Cyclic RGD Peptide Probe. Theranostics. 2012; 2: 746-56.

21. Cui M. Past and Recent Progress of Molecular Imaging Probes for beta-Amyloid Plaques in the Brain. Curr Med Chem. 2014; 21: 82-112.

22. Kim B, Yang J, Hwang M, Choi J, Kim HO, Jang E, et al. Aptamer-modified magnetic nanoprobe for molecular MR imaging of VEGFR2 on angiogenic vasculature. Nanoscale Res Lett. 2013; 8: 399.

23. Varmira K, Hosseinimehr SJ, Noaparast Z, Abedi SM. An improved radiolabelled RNA aptamer molecule for HER2 imaging in cancers. J Drug Target. 2014; 22: 116-22.

24. Olafsen T, Wu AM. Antibody vectors for imaging. Semin Nucl Med. 2010; 40: 167-81.

25. Kaur S, Venktaraman G, Jain M, Senapati S, Garg PK, Batra SK. Recent trends in antibody-based oncologic imaging. Cancer Lett. 2012; 315: 97-111.

26. Holliger P, Hudson PJ. Engineered antibody fragments and the rise of single domains. Nat Biotechnol. 2005; 23: 1126-36.

27. Wu AM, Senter PD. Arming antibodies: prospects and challenges for immunoconjugates. Nat Biotechnol. 2005; 23: 1137-46.

28. Romer T, Leonhardt H, Rothbauer U. Engineering antibodies and proteins for molecular in vivo imaging. Curr Opin Biotechnol. 2011; 22: 882-7.

29. Oliveira S, Heukers R, Sornkom J, Kok RJ, van Bergen En Henegouwen PM. Targeting tumors with nanobodies for cancer imaging and therapy. J Control Release. 2013;172: 607-17.

30. Schoonooghe S, Laoui D, Van Ginderachter JA, Devoogdt N, Lahoutte T, De Baetselier $\mathrm{P}$, et al. Novel applications of nanobodies for in vivo bio-imaging of inflamed tissues in inflammatory diseases and cancer. Immunobiology. 2012; 217: 1266-72.

31. Devoogdt N, Xavier C, Hernot S, Vaneycken I, D'Huyvetter M, De Vos J, et al. Molecular imaging using Nanobodies: a case study. Methods Mol Biol. 2012; 911: 559-67.

32. De Groeve K, Deschacht N, De Koninck C, Caveliers V, Lahoutte T, Devoogdt $\mathrm{N}$, et al. Nanobodies as tools for in vivo imaging of specific immune cell types. J Nucl Med. 2010; 51: 782-9.

33. De Vos J, Devoogdt N, Lahoutte T, Muyldermans S. Camelid single-domain antibody-fragment engineering for (pre)clinical in vivo molecular imaging applications: adjusting the bullet to its target. Expert Opin Biol Ther. 2013; 13: $1149-60$.

34. Smolarek D, Bertrand O, Czerwinski M. Variable fragments of heavy chain antibodies (VHHs): a new magic bullet molecule of medicine? Postepy Hig Med Dosw (Online). 2012; 66: 348-58.

35. Revets H, De Baetselier P, Muyldermans S. Nanobodies as novel agents for cancer therapy. Expert Opin Biol Ther. 2005; 5: 111-24.

36. Muyldermans S, Baral TN, Retamozzo VC, De Baetselier P, De Genst E, Kinne $\mathrm{J}$, et al. Camelid immunoglobulins and nanobody technology. Vet Immunol Immunopathol. 2009; 128: 178-83.

37. Hassanzadeh-Ghassabeh G, Devoogdt N, De Pauw P, Vincke C, Muyldermans S. Nanobodies and their potential applications. Nanomedicine (Lond). 2013; 8: 1013-26.

38. Vaneycken I, D'Huyvetter M, Hernot S, De Vos J, Xavier C, Devoogdt N, et al. Immuno-imaging using nanobodies. Curr Opin Biotechnol. 2011; 22: 877-81.

39. Vincke C, Loris R, Saerens D, Martinez-Rodriguez S, Muyldermans S, Conrath K. General strategy to humanize a camelid single-domain antibody and identification of a universal humanized nanobody scaffold. J Biol Chem. 2009; 284: 3273-84.

40. Harmsen MM, De Haard HJ. Properties, production, and applications of camelid single-domain antibody fragments. Appl Microbiol Biotechnol. 2007; 77: $13-22$.

41. Xavier C, Vaneycken I, D'Huyvetter M, Heemskerk J, Keyaerts M, Vincke C, et al. Synthesis, preclinical validation, dosimetry, and toxicity of ${ }^{68}$ Ga-NOTA-anti-HER2 Nanobodies for iPET imaging of HER2 receptor expression in cancer. J Nucl Med. 2013; 54: 776-84.

42. Huang L, Gainkam LO, Caveliers V, Vanhove C, Keyaerts M, De Baetselier P, et al. SPECT imaging with $99 \mathrm{mTc}$-labeled EGFR-specific nanobody for in vivo monitoring of EGFR expression. Mol Imaging Biol. 2008; 10: 167-75.
43. Gainkam LO, Caveliers V, Devoogdt N, Vanhove C, Xavier C, Boerman O, et al. Localization, mechanism and reduction of renal retention of technetium-99m labeled epidermal growth factor receptor-specific nanobody in mice. Contrast Media Mol Imaging. 2011; 6: 85-92.

44. Vosjan MJ, Perk LR, Roovers RC, Visser GW, Stigter-van Walsum M, van Bergen En Henegouwen PM, et al. Facile labelling of an anti-epidermal growth factor receptor Nanobody with ${ }^{68} \mathrm{Ga}$ via a novel bifunctional desferal chelate for immuno-PET. Eur J Nucl Med Mol Imaging. 2011; 38: 753-63.

45. Oliveira S, van Dongen GA, Stigter-van Walsum M, Roovers RC, Stam JC, Mali W, et al. Rapid visualization of human tumor xenografts through optical imaging with a near-infrared fluorescent anti-epidermal growth factor receptor nanobody. Mol Imaging. 2012; 11: 33-46.

46. Lemaire M, D'Huyvetter M, Lahoutte T, Van Valckenborgh E, Menu E, De Bruyne E, et al. Imaging and radioimmunotherapy of multiple myeloma with anti-idiotypic Nanobodies. Leukemia. 2013; ePub.

47. Ladenson RC, Crimmins DL, Landt Y, Ladenson JH. Isolation and characterization of a thermally stable recombinant anti-caffeine heavy-chain antibody fragment. Anal Chem. 2006; 78: 4501-8.

48. Muyldermans S. Nanobodies: natural single-domain antibodies. Annu Rev Biochem. 2013; 82: 775-97.

49. Wu TT, Johnson G, Kabat EA. Length distribution of CDRH3 in antibodies. Proteins. 1993; 16: 1-7.

50. Wesolowski J, Alzogaray V, Reyelt J, Unger M, Juarez K, Urrutia M, et al. Single domain antibodies: promising experimental and therapeutic tools in infection and immunity. Med Microbiol Immunol. 2009; 198: 157-74.

51. Zabetakis D, Anderson GP, Bayya N, Goldman ER. Contributions of the complementarity determining regions to the thermal stability of a single-domain antibody. PLoS One. 2013; 8: e77678.

52. Kuroda D, Shirai H, Jacobson MP, Nakamura H. Computer-aided antibody design. Protein Eng Des Sel. 2012; 25: 507-21.

53. Kijanka M, Warnders FJ, El Khattabi M, Lub-de Hooge M, van Dam GM, Ntziachristos V, et al. Rapid optical imaging of human breast tumour xenografts using anti-HER2 VHHs site-directly conjugated to IRDye $800 \mathrm{CW}$ for image-guided surgery. Eur J Nucl Med Mol Imaging. 2013; 40: 1718-29.

54. Movahedi K, Schoonooghe S, Laoui D, Houbracken I, Waelput W, Breckpot K, et al. Nanobody-based targeting of the macrophage mannose receptor for effective in vivo imaging of tumor-associated macrophages. Cancer Res. 2012; 72: 4165-77.

55. Cortez-Retamozo V LT, Caveliers V, Gainkam LOT, Hernot S,. ${ }^{99 m T c-L a b e l e d ~}$ Nanobodies: A New Type of Targeted Probes for Imaging Antigen Expression. Current Radiopharm. 2008; 1: 37-41.

56. Vosjan MJ, Vercammen J, Kolkman JA, Stigter-van Walsum M, Revets H, van Dongen GA. Nanobodies targeting the hepatocyte growth factor: potential new drugs for molecular cancer therapy. Mol Cancer Ther. 2012; 11: 1017-25.

57. Tijink BM, Laeremans T, Budde M, Stigter-van Walsum M, Dreier T, de Haard $\mathrm{HJ}$, et al. Improved tumor targeting of anti-epidermal growth factor receptor Nanobodies through albumin binding: taking advantage of modular Nanobody technology. Mol Cancer Ther. 2008; 7: 2288-97.

58. Jiang W, Rosenberg JN, Wauchope AD, Tremblay JM, Shoemaker CB, Weeks $\mathrm{DP}$, et al. Generation of a phage-display library of single-domain camelid $\mathrm{VH}$ $\mathrm{H}$ antibodies directed against Chlamydomonas reinhardtii antigens, and characterization of $\mathrm{VH}$ Hs binding cell-surface antigens. Plant J. 2013; 76: 709-17.

59. Vaneycken I, Devoogdt N, Van Gassen N, Vincke C, Xavier C, Wernery U, et al. Preclinical screening of anti-HER2 nanobodies for molecular imaging of breast cancer. FASEB J. 2011; 25: 2433-46.

60. Gomes CM, Abrunhosa AJ, Ramos P, Pauwels EK. Molecular imaging with SPECT as a tool for drug development. Adv Drug Deliv Rev. 2011; 63: 547-54.

61. Ametamey SM, Honer M, Schubiger PA. Molecular imaging with PET. Chem Rev. 2008; 108: 1501-16

62. Alauddin MM. Positron emission tomography (PET) imaging with ${ }^{18} \mathrm{~F}-\mathrm{based}$ radiotracers. Am J Nucl Med Mol Imaging. 2012; 2: 55-76.

63. Holland JP, Cumming P, Vasdev N. PET radiopharmaceuticals for probing enzymes in the brain. Am J Nucl Med Mol Imaging. 2013; 3: 194-216.

64. Eckelman WC. Unparalleled contribution of technetium-99m to medicine over 5 decades. JACC Cardiovasc Imaging. 2009; 2: 364-8.

65. Chakravarty R, Shukla R, Ram R, Venkatesh M, Dash A, Tyagi AK. Nanoceria-PAN composite-based advanced sorbent material: a major step forward in the field of clinical-grade ${ }^{68} \mathrm{Ge} /{ }^{68} \mathrm{Ga}$ generator. ACS Appl Mater Interfaces. 2010; 2: 2069-75

66. van der Meel R, Gallagher WM, Oliveira S, O'Connor AE, Schiffelers RM, Byrne AT. Recent advances in molecular imaging biomarkers in cancer: application of bench to bedside technologies. Drug Discov Today. 2010; 15: 102-14.

67. James ML, Gambhir SS. A molecular imaging primer: modalities, imaging agents, and applications. Physiol Rev. 2012; 92: 897-965.

68. Hellebust A, Richards-Kortum R. Advances in molecular imaging: targeted optical contrast agents for cancer diagnostics. Nanomedicine (Lond). 2012; 7: 429-45.

69. Luker GD, Luker KE. Optical imaging: current applications and future directions. J Nucl Med. 2008; 49: 1-4.

70. Ntziachristos V, Razansky D. Optical and opto-acoustic imaging. Recent Results Cancer Res. 2013; 187: 133-50.

71. van Dam GM, Themelis G, Crane LM, Harlaar NJ, Pleijhuis RG, Kelder W, et al. Intraoperative tumor-specific fluorescence imaging in ovarian cancer by 
folate receptor-alpha targeting: first in-human results. Nat Med. 2011; 17: 1315-9.

72. Vahrmeijer AL, Hutteman M, van der Vorst JR, van de Velde CJ, Frangioni JV. Image-guided cancer surgery using near-infrared fluorescence. Nat Rev Clin Oncol. 2013; 10: 507-18.

73. Postema M, Gilja OH. Contrast-enhanced and targeted ultrasound. World J Gastroenterol. 2011; 17: 28-41.

74. Lindner JR, Wei K. Contrast echocardiography. Curr Probl Cardiol. 2002; 27: 454-519.

75. Neshat H, Cool DW, Barker K, Gardi L, Kakani N, Fenster A. A 3D ultrasound scanning system for image guided liver interventions. Med Phys. 2013; 40: 112903.

76. Mui LW, Pursell LJ, Botwinick IC, Allendorf JD, Chabot JA, Newhouse JH. Routine intraoperative hepatic sonography does not affect staging or postsurgical hepatic recurrence in pancreatic adenocarcinoma. J Ultrasound Med. 2014; 33: 47-51.

77. Hernot S, Unnikrishnan S, Du Z, Shevchenko T, Cosyns B, Broisat A, et al. Nanobody-coupled microbubbles as novel molecular tracer. J Control Release. 2012; 158: 346-53.

78. Arteaga CL. Epidermal growth factor receptor dependence in human tumors: more than just expression? Oncologist. 2002; 7 Suppl 4: 31-9.

79. Cai W, Niu G, Chen X. Multimodality imaging of the HER-kinase axis in cancer. Eur J Nucl Med Mol Imaging. 2008; 35: 186-208.

80. Altintas I, Kok RJ, Schiffelers RM. Targeting epidermal growth factor receptor in tumors: from conventional monoclonal antibodies via heavy chain-only antibodies to nanobodies. Eur J Pharm Sci. 2012; 45: 399-407.

81. Gainkam LO, Huang L, Caveliers V, Keyaerts M, Hernot S, Vaneycken I, et al. Comparison of the biodistribution and tumor targeting of two ${ }^{99 \mathrm{mTc}} \mathrm{Tc}-\mathrm{abeled}$ anti-EGFR nanobodies in mice, using pinhole SPECT/micro-CT. J Nucl Med. 2008; 49: 788-95.

82. Gainkam LO, Keyaerts M, Caveliers V, Devoogdt N, Vanhove C, Van Grunsven L, et al. Correlation between epidermal growth factor receptor-specific nanobody uptake and tumor burden: a tool for noninvasive monitoring of tumor response to therapy. Mol Imaging Biol. 2011; 13: 940-8.

83. Capala J, Bouchelouche K. Molecular imaging of HER2-positive breast cancer: a step toward an individualized 'image and treat' strategy. Curr Opin Oncol. 2010; 22: 559-66.

84. Niu G, Cai W, Chen X. Molecular imaging of human epidermal growth factor receptor 2 (HER-2) expression. Front Biosci. 2008; 13: 790-805.

85. Pruszynski M, Koumarianou E, Vaidyanathan G, Revets H, Devoogdt N, Lahoutte $\mathrm{T}$, et al. Targeting breast carcinoma with radioiodinated anti-HER2 Nanobody. Nucl Med Biol. 2013; 40: 52-9.

86. Nakamura T, Mizuno S. The discovery of hepatocyte growth factor (HGF) and its significance for cell biology, life sciences and clinical medicine. Proc Jpn Acad Ser B Phys Biol Sci. 2010; 86: 588-610.

87. Bottaro DP, Rubin JS, Faletto DL, Chan AM, Kmiecik TE, Vande Woude GF, et al. Identification of the hepatocyte growth factor receptor as the c-met proto-oncogene product. Science. 1991; 251: 802-4.

88. Birchmeier C, Birchmeier W, Gherardi E, Vande Woude GF. Met, metastasis, motility and more. Nat Rev Mol Cell Biol. 2003; 4: 915-25.

89. Leung K. ${ }^{89} \mathrm{Zr}$-Desferrioxamine p-isothiocyanatobenzyl-anti-hepatocyte growth factor nanobody 1E2 fused to albumin-binding nanobody Alb8. Molecular Imaging and Contrast Agent Database (MICAD). Bethesda MD; 2004.

90. Harris N, Super M, Rits M, Chang G, Ezekowitz RA. Characterization of the murine macrophage mannose receptor: demonstration that the downregulation of receptor expression mediated by interferon-gamma occurs at the level of transcription. Blood. 1992; 80: 2363-73.

91. Movahedi K, Laoui D, Gysemans C, Baeten M, Stange G, Van den Bossche I, et al. Different tumor microenvironments contain functionally distinct subsets of macrophages derived from Ly6C(high) monocytes. Cancer Res. 2010; 70: 5728-39.

92. Kurachi T, Morita I, Oki T, Ueki T, Sakaguchi K, Enomoto S, et al. Expression on outer membranes of mannose residues, which are involved in osteoclast formation via cellular fusion events. J Biol Chem. 1994; 269: 17572-6.

93. Morishima S, Morita I, Tokushima T, Kawashima H, Miyasaka M, Omura K, et al. Expression and role of mannose receptor/terminal high-mannose type oligosaccharide on osteoclast precursors during osteoclast formation. J Endocrinol. 2003; 176: 285-92.

94. Maruotti N, Grano M, Colucci S, d'Onofrio F, Cantatore FP. Osteoclastogenesis and arthritis. Clin Exp Med. 2011; 11: 137-45.

95. Put S, Schoonooghe S, Devoogdt N, Schurgers E, Avau A, Mitera T, et al. SPECT imaging of joint inflammation with Nanobodies targeting the macrophage mannose receptor in a mouse model for rheumatoid arthritis. J Nucl Med. 2013; 54: 807-14.

96. Cybulsky MI, Fries JW, Williams AJ, Sultan P, Eddy R, Byers M, et al. Gene structure, chromosomal location, and basis for alternative mRNA splicing of the human VCAM1 gene. Proc Natl Acad Sci U S A. 1991; 88: 7859-63.

97. Cybulsky MI, Gimbrone MA, Jr. Endothelial expression of a mononuclear leukocyte adhesion molecule during atherogenesis. Science. 1991; 251: 788-91.

98. Li H, Cybulsky MI, Gimbrone MA, Jr., Libby P. An atherogenic diet rapidly induces VCAM-1, a cytokine-regulatable mononuclear leukocyte adhesion molecule, in rabbit aortic endothelium. Arterioscler Thromb. 1993; 13: 197-204.

99. Li H, Cybulsky MI, Gimbrone MA, Jr., Libby P. Inducible expression of vascular cell adhesion molecule-1 by vascular smooth muscle cells in vitro and within rabbit atheroma. Am J Pathol. 1993; 143: 1551-9.
100. McAteer MA, Choudhury RP. Targeted molecular imaging of vascular inflammation in cardiovascular disease using nano- and micro-sized agents. Vascul Pharmacol. 2013; 58: 31-8.

101. Broisat A, Hernot S, Toczek J, De Vos J, Riou LM, Martin S, et al. Nanobodies targeting mouse/human VCAM1 for the nuclear imaging of atherosclerotic lesions. Circ Res. 2012; 110: 927-37.

102. Nahrendorf M, McCarthy JR, Libby P. Over a hump for imaging atherosclerosis: nanobodies visualize vascular cell adhesion molecule-1 in inflamed plaque. Circ Res. 2012; 110: 902-3.

103. Hong H, Sun J, Cai W. Radionuclide-Based Cancer Imaging Targeting the Carcinoembryonic Antigen. Biomark Insights. 2008; 3: 435-51.

104. Choi KY, Liu G, Lee S, Chen X. Theranostic nanoplatforms for simultaneous cancer imaging and therapy: current approaches and future perspectives. Nanoscale. 2012; 4: 330-42.

105. Xie J, Lee S, Chen X. Nanoparticle-based theranostic agents. Adv Drug Deliv Rev. 2010; 62: 1064-79.

106. Chen F, Ellison PA, Lewis CM, Hong H, Zhang Y, Shi S, et al. Chelator-Free Synthesis of a Dual-Modality PET/MRI Agent. Angew Chem Int Ed Engl. 2013; 52: 13319-23.

107. Chen F, Hong H, Zhang Y, Valdovinos HF, Shi S, Kwon GS, et al. In vivo tumor targeting and image-guided drug delivery with antibody-conjugated, radiolabeled mesoporous silica nanoparticles. ACS Nano. 2013; 7: 9027-39.

108. Goel S, Chen F, Cai W. Synthesis and Biomedical Applications of Copper Sulfide Nanoparticles: From Sensors to Theranostics. Small. 2013; ePub.

109. Shi S, Chen F, Cai W. Biomedical applications of functionalized hollow mesoporous silica nanoparticles: focusing on molecular imaging. Nanomedicine (Lond). 2013; 8: 2027-39.

110. Yang K, Feng L, Hong H, Cai W, Liu Z. Preparation and functionalization of graphene nanocomposites for biomedical applications. Nat Protoc. 2013; 8: 2392-403.

111. Sun Y, Zhu X, Peng J, Li F. Core-shell lanthanide upconversion nanophosphors as four-modal probes for tumor angiogenesis imaging. ACS Nano. 2013; 7: 11290-300

112. Gong H, Peng R, Liu Z. Carbon nanotubes for biomedical imaging: The recent advances. Adv Drug Deliv Rev. 2013; 65: 1951-63.

113. Kim YH, Jeon J, Hong SH, Rhim WK, Lee YS, Youn H, et al. Tumor targeting and imaging using cyclic RGD-PEGylated gold nanoparticle probes with directly conjugated iodine-125. Small. 2011; 7: 2052-60.

114. Sharma A, Jain N, Sareen R. Nanocarriers for diagnosis and targeting of breast cancer. Biomed Res Int. 2013; 2013: 960821

115. Yoo JW, Chambers E, Mitragotri S. Factors that control the circulation time of nanoparticles in blood: challenges, solutions and future prospects. Curr Pharm Des. 2010; 16: 2298-307.

116. Riehemann K, Schneider SW, Luger TA, Godin B, Ferrari M, Fuchs H. Nanomedicine--challenge and perspectives. Angew Chem Int Ed Engl. 2009; 48: 872-97.

117. Sanhai WR, Sakamoto JH, Canady R, Ferrari M. Seven challenges for nanomedicine. Nat Nanotechnol. 2008; 3: 242-4. 